\title{
Rare Case of Acute Peritonitis by Perforation of an Appendicular Schistosomiasis at the CHU BSS in Kati
}

\author{
Koniba Keita1 ${ }^{*}$, Abdoulaye Diarra1, Sidiki Keita², Oulématou Coulibaly3 , Assitan Koné1, \\ Salia Coulibaly4, Amadou Traoré5, Idrissa Tounkara5, Lamine Soumaré2, Mamadou Diallo3, \\ Bourama Togola ${ }^{2}$, Drissa Traoré ${ }^{2}$, Pierre A. Togo ${ }^{5}$
}

${ }^{1}$ Department of General Surgery, CHU BSS, Kati, Mali

${ }^{2}$ Department of General Surgery, CHU Point-G, Bamako, Mali

${ }^{3}$ Reference health center of the commune VI of the district of Bamako, Bamako, Mali

${ }^{4}$ Medical Imaging Department, CHU BSS, Kati, Mali

${ }^{5}$ General Surgery Department, CHU Gabriel Touré, Bamako, Mali

Email: *koniskeita73@gmail.com

How to cite this paper: Keita, K., Diarra, A., Keita, S., Coulibaly, O., Koné, A., Coulibaly, S., Traoré, A., Tounkara, I., Soumaré, L., Diallo, M., Togola, B., Traoré, D. and Togo, P.A. (2020) Rare Case of Acute Peritonitis by Perforation of an Appendicular Schistosomiasis at the CHU BSS in Kati. Surgical Science, 11, 385-392. https://doi.org/10.4236/ss.2020.1112040

Received: August 20, 2020

Accepted: December 4, 2020

Published: December 7, 2020

Copyright $\odot 2020$ by author(s) and Scientific Research Publishing Inc. This work is licensed under the Creative Commons Attribution International License (CC BY 4.0).

http://creativecommons.org/licenses/by/4.0/

\begin{abstract}
Perforation of a pseudo appendicular tumor of bilharzial origin (bilharzia) is a rare etiology of acute peritonitis. His diagnosis is histopathological. The existence of comorbid malaria and surgical pathology is frequent in having a positive thick drop with Schistosoma mansoni eggs in his stool. After 3 months, the patient is doing well. In conclusion, we recommend the histopathological analysis of the surgical specimen after appendectomy and the detection of haematozoa for malaria in any case of fever in a surgical environment.
\end{abstract}

\section{Keywords}

Acute Peritonitis, Bilharzia, Ileocecal Appendix

\section{Introduction}

Abdominal-surgical emergencies are dominated in Africa particularly in the south of the Sahara by acute peritonitis [1]. Among these, appendicular and ileal perforations of typhoid origin are the most frequent [2] [3]. However, perforation of appendicular bilharzia in the free peritoneum causing acute peritonitis is an entity rarely cited in the literature. Peritonitis is defined as an acute inflammation of the peritoneum, localized or generalized, the cause of which is most 
often infectious. Not taken care of in a short time, local complications then generally occur and threaten the life of the patient. Peritonitis is divided into three groups according to the Hamburg classification according to the origin of the infection:

-Primary peritonitis: These are due to a spontaneous mono-bacterial infection of the peritoneum of hematogenous origin or by translocation. Their treatment is medical. The most common causes are ascites infection with Escherichia coli in cirrhotic patients, staphylococcal infection via the catheter in patients with peritoneal dialysis and spontaneous pneumococcal peritonitis in adults.

-Secondary peritonitis represents $90 \%$ of peritonitis. They are linked to the spread of a localized abdominal infection or the perforation of digestive viscera. The main causes are dominated by appendicular perforations, typhoid, gastric ulcers and diverticular perforations. These secondary peritonitis are associated with postoperative peritonitis by anastomotic laceration or by fistula.

-Tertiary peritonitis corresponds to persistent abdominal infections despite a well-conducted treatment (adapted antibiotic therapy and eradication of the primary abdominal focus by one or more interventions). The abdominal cavity is superinfected by microorganisms that are not very virulent but have become resistant or yeasts. These peritonitis are frequently associated with multiorgan failure syndrome.

Bilharzia is an old pathology whose first writings date back to $1500 \mathrm{BC}$ in the Ebert papyrus. It is rampant in the tropics and subtropics in an endemic state and constitutes a real public health problem [4].

In Mali, it is the second most important parasitic disease [6] after malaria. Two forms are present: the urogenital form due to Schistosoma haematobium (S. haematobium), the prevalence of which reaches $72 \%$, and the intestinal form linked to Schistosoma mansoni (S. mansoni) 68\% in certain areas of the country [7]. Appendicular schistosomiasis is a rare pathology, and exclusively for histopathological diagnosis [8] [9] [10]. We report a rare case of acute peritonitis by perforation of an appendicular pseudotumor of bilharzia origin (bilharzia) in the general surgery department of the CHU BSS in Kati.

\section{Observation}

It was a 19 -year-old male patient, a shepherd by profession, weighing 52 kilograms, living in a rural area. He said he frequently bathes in the water reservoirs of micro dams in their area. He was urgently admitted to the CHU BSS in Kati for painful abdominal distension with fever of $39^{\circ} \mathrm{C}$ and vomiting of food. Symptoms began 4 days earlier in the right iliac fossa following dysenteriform, bloody diarrhea. In his history, the patient reported having resolving episodic chronic pain in the right iliac fossa with saddles often streaked with blood for more than six months. On clinical examination he presented with painful abdominal distension, motionless, with cry of the umbilicus, dullness of wood and disappearance of prehepatic dullness. On digital rectal examination the Douglas 
was bulging and painful and the finger cot came back soiled with greenish mucus stool streaked with blood. On the X-ray of the abdomen without preparation (ASP), a gas crescent under the right diaphragm was observed on the image (Figure 1). Biologically, we observed: hyper leukocytosis at $17.3 \times 10^{3} / \mathrm{mm}^{3}$, hemoglobin level at $10 \mathrm{~g} / \mathrm{dl}$, eosinophilia rate at $8 \%$. The thick blot had come back positive 100 trophozoites of Plasmodium falciparum per field. The diagnosis of acute peritonitis by perforation of a hollow organ on a site of malaria was retained. The patient was immediately put on an injectable arthesum protocol. At the midline supra and subumbilical laparotomy, 800 centiliters of seropurulent fluid was aspirated from the peritoneal cavity. The ileocecal appendix was large, swollen, pseudo-tumor at its apex (bell-clapper appearance), perforated with areas of necrosis (Figure 2 and Figure 3). Exploration did not find any deep

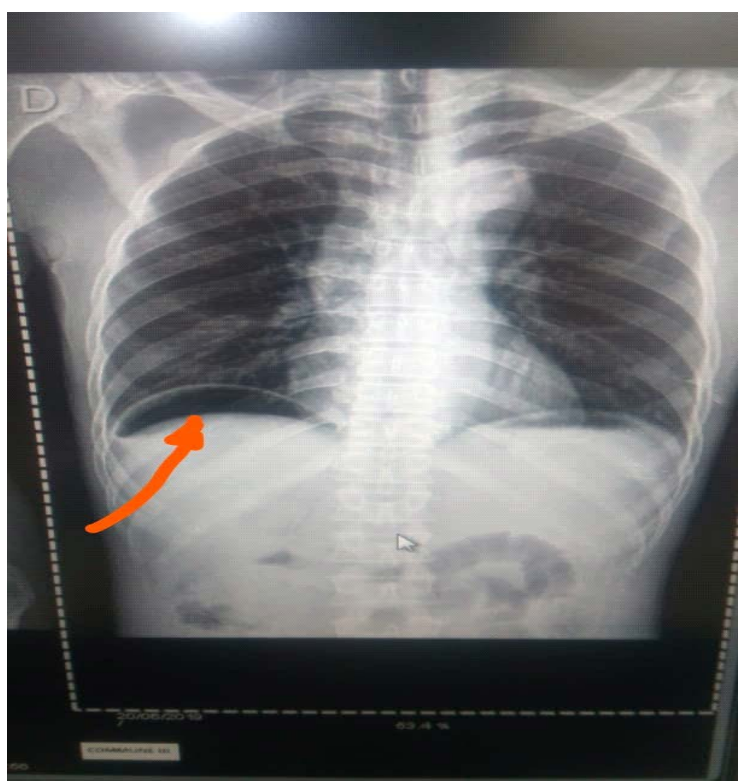

Figure 1. Right interhepato-diaphragmatic gas crescent.

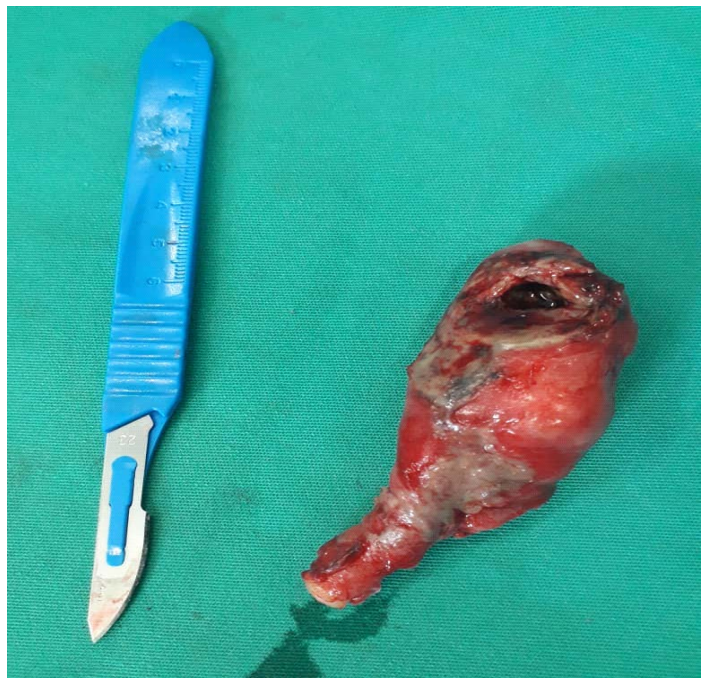

Figure 2. Appendicular bilharzia necrotic and perforated. 
ileocecal lymphadenopathy and the liver was intact. We performed the non-burial appendectomy. Peritoneal lavage with lukewarm saline, 4 liters, drainage and closure of the abdominal cavity. The diagnosis of acute peritonitis by perforation of appendicular tumor was retained. Cytobacteriological analysis and antibiogram showed the presence of Helicobacter pylori in the pus, sensitive to Ceftriaxone. The patient was put under this molecule at a rate of $1 \mathrm{~g}$ every 12 hours and metronidazole infusion $500 \mathrm{mg}$ every 8 hours. The operative consequences were simple. The patient was released on the $7^{\text {th }}$ day. Histopathological examination of the operative specimen (Figure 4) 3 weeks later concluded in a perforated appendicular schistosomiasis with peritoneal reaction and the presence of calcified schistosomiasis eggs. Absence of histological sign of malignancy at the limit of the fragments observed.

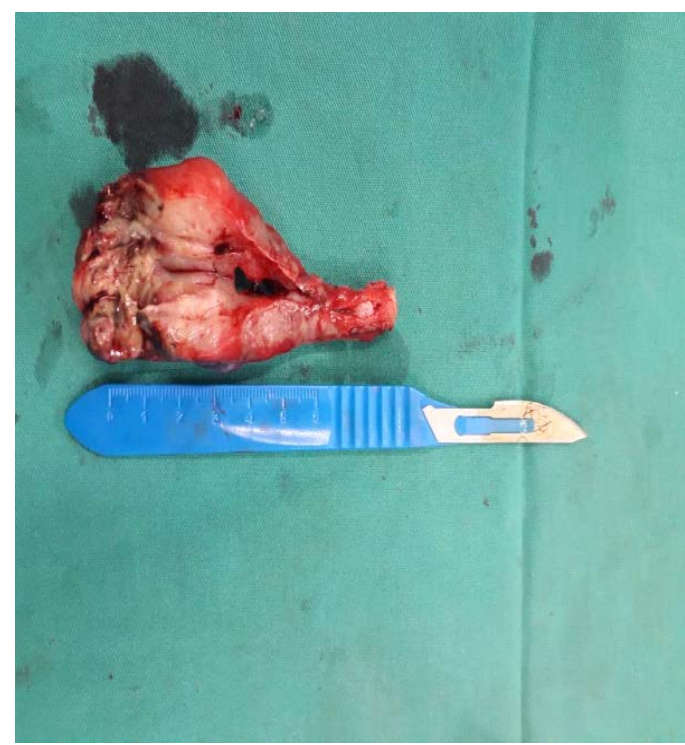

Figure 3. Appendicular bilharzia dissected.

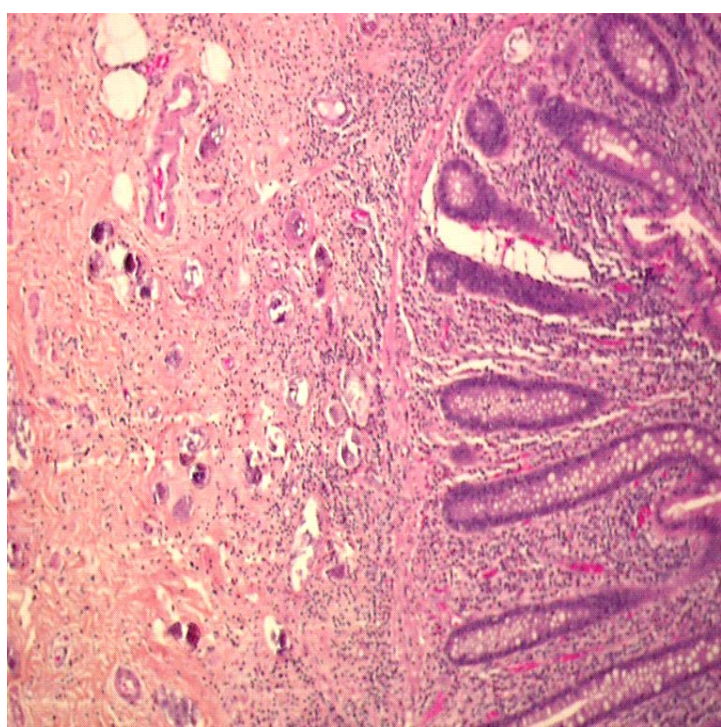

Figure 4. Calcified bilharzia eggs. 


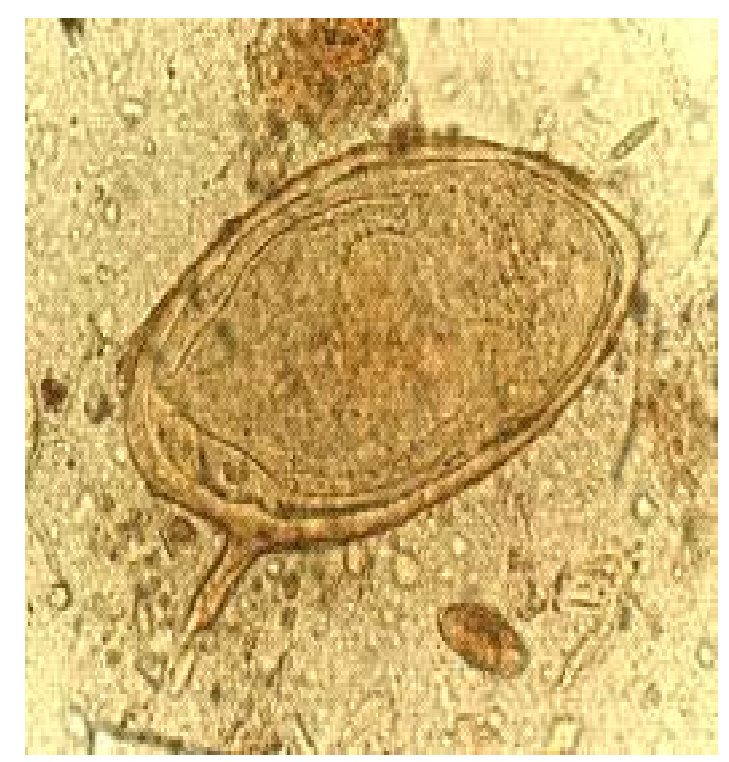

Figure 5. Eggs of Schistosoma mansoni.

Analysis of fresh stool after surgery identified Schistosoma mansoni eggs with their lateral spur (Figure 5). The treatment was completed by the administration of Praziquantel tablet, 2100 milligrams ( 3 tablet $+1 / 2)$ as a single dose. After 3 months, the patient is doing well.

\section{Discussion}

Acute peritonitis by appendicular perforation is the leading cause of peritonitis in Africa. It is followed by typhoid perforation peritonitis [2] [3]. If appendicular perforations of bacterial origin are the best known, the fact remains that the parasites in this case schistosomiasis or bilharzia can also cause this kind of complication. In the patient's history, the notion of chronic pain in the right iliac fossa (RIF) deserves further investigation.

Schistosomiasis is rampant in the tropics and subtropics in an endemic way and constitutes a real public health problem [1]. In Mali, the entire country is affected by this disease [11] [12]. Turner was the first to report in 1909, the first appendicular localization of bilharzia in a series of autopsies [13]. His diagnosis is only pathological. According to the authors, in the African and Asian series [14] [15], bilharzia is rarely implicated in the genesis of appendicular inflammation. Its prevalence ranged from $0.2 \%$ to $2.9 \%$. On the other hand, in Europe, appendicular schistosomiasis is exceptional and is seen mainly in subjects coming from endemic areas [16]. However in Mali, its prevalence appears to be significant. Bayo S [17] in 2000, in a series of 215 pieces examined, found $21 \%$ appendicular schistosomiasis. A decade later Coulibaly MB [18] in 2013 reported 25.5\% tissue localization (bilharzia appendicitis). It should be noted that the first studies on appendicular locations of schistosomes are more than 40 years old. Unlike Thiam I and Ouédraogo Y [9] [10], we believe that the prevalence of appendicular bilharzia is high in endemic African areas. Only a lot of appendecto- 
my pieces do not reach pathology laboratories. And this, not only for pecuniary reasons (refusal of the patient's parents to spend more) but also the concentration of pathology laboratories in the capital city, only to the detriment of the rest of the country). In areas with hydro-agricultural development in Mali such as the Niger rice office, the Dogon plateau and localities located along waterways including the district of Bamako, transmission of schistosomiasis is strong in Mali [19].

Clinically, the patient's history indicated that the pain started in the right iliac fossa. He had a peritoneal face with fever and signs of dehydration. Painful abdominal contracture and cry of the umbilicus were observed. Prehepatic dullness was absent. The notion of intermittent chronic pain of RIF could be explained by the chronic and progressive infestation of the appendix with bilharzia eggs. Intermittent abdominal pain associated with episodic dysenteriform, bloody diarrhea have been reported by the patient. This symptomatology is generally found in infestations with Schistosoma mansoni in an endemic environment [7] [20]. These same authors point out that these two signs could be considered as good indicators of collective diagnosis of Schistosoma mansoni in schools. Analysis of the patient's fresh saddle identified Schistosoma mansoni eggs in the stool (Figure 4) of the patient. If the presence of calcified eggs on the ileocecal appendix denotes the antiquity of the bilharzia infestation, the presence of eggs in the saddles indicates the recent evolution of the bilharzia pathology, especially since the eosinophilia was high (8\%). The patient has not reported a history of hematuria.

In Mali, two forms of bilharzia exist: Bilharzia caused by Schistosoma haematobium and Bilharzia caused by Schistosoma mansoni. The other Schistosoma japonicum Schistosoma intercalatum, Guinean Schistosoma and Schistosoma mecongui species do not exist in the country [7] [11]. As reported in the literature by the authors [9] [10] all appendectomy parts must be histopathologically analyzed. This will provide better information on the prevalence of tissue locations for schistosomiasis in our countries. Therapeutically, the patient received antimalarial treatment (injectable arthesum protocol), as recommended by the World Health Organization (WHO) before the surgery. Malaria is endemic in Mali, a thick drop should be performed in any case of fever in order to know the parasite status of the patient in a hospital environment.

Appendectomy associated with peritoneal lavage with saline was performed to eradicate the cause of acute peritonitis. We administered Praziquantel to the patient postoperatively after resumption of intestinal transit, on the $2^{\text {nd }}$ day of surgery. This was due to the fact that Schistosoma mansoni eggs had been observed in the patient's saddle. This was indicative of an ongoing intestinal schistosomiasis infestation. We did not wait for the result of the exam pathology of the operative part to initiate treatment with Praziquantel. The authors [9] [21] always started this treatment after the result of the histopathological examination due to the fact that appendicular schistosomiasis is histopathologically diag- 
nosed. The administration of Praziquantel to our patient not only treated the current diarrhea but also eradicated any tissue localization of the parasite as reported in the literature [9] [10].

\section{Conclusion}

Bilharz infestation of the ileocecal appendix can cause an appendicular pseudotumor. Its treatment is medico-surgical. The histopathological examination must be rigorous in front of any piece of appendectomy.

\section{Conflicts of Interest}

The authors declare no conflicts of interest regarding the publication of this paper.

\section{References}

[1] Monteiro, M.C., Daniélou, A., Piémont, Y., Hansmann, Y. and Rohr, S. (2007) Microbiological Samples and Probabilistic Antibiotic Treatments for Secondary Community Peritonitis. Journal de Chirurgie, 144, 486-491. https://doi.org/10.1016/S0021-7697(07)79773-9

[2] Keita, K., Diarra, A.G., Coulibaly, O., Diallo, M., Traoré, L.T., Keita, F., Koné, A., et al. (2020) Acute Peritonitis at Kati BSS CHU: Etiological and Therapeutic Aspect. JACCR Africa, 4, 366-372.

[3] Amadou, H., Abou, O., Amadou, M.L., Magagi, A., Amadou, M. and Sani, R. (2016) Etiologie et traitement des péritonites aigues à l'hôpital National de Zender: À propos de 313 patients. Rév. Afr. Chir. Spéc, 1, 12-18.

[4] Guiguen, C., Belaz, S., Robert-Gangneux, F. and Gangneux, J.P. (2013) Bilharziasis: Epidemioclinical and Diagnostic Aspects. Revue Francophone des Laboratoires, 457, 75-85. https://doi.org/10.1016/S1773-035X(13)72269-X

[5] Aubry, P. (2014) Schistosomes ou Bilharzioses: 2014 News. Bilharzia Update. http://medecinetropicale.free.fr/cours/schistosomose

[6] Traoré, M., Landouré, A., Diarra, A., Kanté, B., Sacko, M., Coulibaly, G., Sangho, A. and Simaga, Y. (2017) Ecoclimatic Diversity and the Epidemiology of Schistosomiasis in Mali, Implication for a Control Program. Mali Medical, 22, 22-26.

[7] Sangho, H., Dabo, A., Sangho, O., Diawara, A. and Doumbo, O. (2005) Prevalence and Perception of Schistosomiasis in Irrigated Rice Growing Areas in Mali. Maliméd, 20, 15-20.

[8] Bourée, P., Bisaro, F., Kanner, A. and Djibo, N. (2008) Appendicites parasitaires. Revue Francophone des Laboratoires, 399, 79-86. https://doi.org/10.1016/S1773-035X(08)70184-9

[9] Thiam, I., Doh, K., Seck, M., Kammoun, C. and Woto-Gaye, G. (2015) Appendicite Bilharzienne: A Rare Lesion in Two Cases in Senegal. Bulletin de la Société de pathologie exotique, 108, 161-164. https://doi.org/10.1007/s13149-015-0432-7

[10] Bazongo, M., Ouédraogo, A.S., Zida, M., Bonkoungo, G.P., Ouangré, E., Sanou, A., Doamba, N.R., Zongo, N., Sawadogo, Y.E. and Traoré, S.S. (2017) Acute Appendicitis Linked to Bilharzia: About Four Cases at the CHU Yalgado Ouédraogo (YO) in Ouagadougou. Médecine et Santé Tropicales, 27, 333-335.

https://doi.org/10.1684/mst.2017.0694 
[11] Dabo, A., Doucouré, B., Koita, O., Diallo, M., Kouriba, B., Klinkert, M.Q., Doumbia, S. and Doumbo, O. (2000) Reinfection with Schistosoma heamatobium and Mansoni at the Office du Niger in Mali despite Repeated Use of Praziquantel. Médicinetropicale: Revue du Corps de Santé Colonial, 60, 351-355.

[12] Keita, A.D., Dembele, M., Kane, M., Fongoro, S., Traoré, M., Diallo, S., et al. (2001) Ultrasound Aspects of Urinary Schistosomiasis in Children of the Dogon Plateau and the Niger Office; Impact of Treatment with Praziquantel. Bulletin de la Société de Pathologie Exotique, 94, 335-338.

[13] Hodasi, W.M. (1988) Schistosoma Appendicitis. Tropical Doctor, 18, 105-106. https://doi.org/10.1177/004947558801800305

[14] Chan, K.W., Fu, K.H. and Ling, J. (1998) The Pathology of the Appendix in Hong Kong. British Journal of Clinical Pharmacology, 42, 241-244.

[15] Adebamowo, C.A., Akang, E.E., Ladipo, J.K. and Ajao, O.G. (1991) Schistosomiasis of the Appendix. British Journal of Surgery, 78, 1219-1221. https://doi.org/10.1002/bjs.1800781023

[16] Jones, H.J., Ibrahim, A.E. and Deroda, J.K. (1997) Schistosomiasis of the Appendix in the UK. British Journal of Clinical Pharmacology, 51, 183.

[17] Bayo, S., Kamaté, B., Sacko, M., Traoré, C. and Touré, A. (2000) Tissue Schistosomiasis in Mali in the Case of 215 Cases. Mali Médical, 15, 29-31.

[18] Coulibaly, M.B. (2013) Tissue Schistosomiasis in Mali about 145 Cases in the Anatomy and Pathological Cytology Department of the Chu du Point-G. Thèse Méd.

[19] Ndiaye, F. (2009) Impact of Mass Treatment with Praziquantel on Morbidity Due to Schistosomiasis in the District of Bamako and the Circle of Kati. Thesis Med.

[20] Utsinger, J., N’goran, E.K., Ossey, Y.A., Booth, M., Traore, M., Lohonrignon, K.L. et al. (2000) Rapid Screening for Schistosoma mansoni in Western Côte d'Ivoire Using a Simple School Questionnaire. Bulletin of the World Health Organization, 78, 389-398.

[21] Ahmed, S.A., Mohammed, U. and Sanda, R.B. (2014) Schistosomiasis of the Appendix in a Tertiary Hospital in Northern Nigeria. A 22-Year Review. Journal of Laboratory Physicians, 6, 18-21. https://doi.org/10.4103/0974-2727.129085 